\title{
Searching for Knowledge: Teaching Information Technology to Secondary Students
}

\author{
Eleanor B. Howe \\ Librarian, Pine-Richland High School \\ 4499 Birchwood Lane \\ Allison Park, PA 15101 \\ USA \\ ehowe@prsd.k12.pa.us
}

\begin{abstract}
This paper discusses the importance of accurate knowledge to a knowledgebased society and presents the rationale, organization, and content of a short course in electronic search skills that enables students to retrieve accurate information by evaluating their searches, citations, and resources in a variety of databases. Focusing on the Seven Steps in the electronic search process, the course develops students' skills in thinking, computer literacy, and the ethical use of information. Students learn the concepts, process, and skills of information literacy and technology as they integrate the results of their searches into subject areas across the secondary curriculum. A syllabus and daily topics are included.
\end{abstract}

Although many administrators may have what Ken Haycock has called "technolust," information technologies can and should provide real and increased knowledge for students. These technologies, no matter how simple or sophisticated, are a means of storing and accessing the knowledge and resources that learners select and use to create new knowledge of their own. When new knowledge is publicly disseminated it becomes the knowledge of the society, which must be built on accurate knowledge that is cumulated. Libraries, especially those associated with educational institutions, play a vital role in collecting and disseminating knowledge. Indeed, they can be viewed as a repository of the documented knowledge and creativity of a society and a means of passing that achievement on to the next generation.

\section{Knowledge, Missions, and Goals}

A "knowledge society" is one that uses knowledge as a basic means of maintaining and improving itself. To do this, members of the society locate, select, evaluate, use, create, and communicate information and knowledge; and they use previously demonstrated and authoritative knowledge to build new knowledge. This process sounds very much like a definition of information skills, and educational institutions and their libraries do have important functions in developing and maintaining a knowledge society. Information Power 1998 focuses on the contributions of school libraries and teacher-librarians to the development of student knowledge by providing instruction, quality library services, and effective program administration (AASL \& AECT, 1998).

In order for students to contribute to their own learning and to a knowledge society, they must learn how to acquire and communicate knowledge by using current information technologies to obtain a variety of both print and electronic resources through library collections and access services. They must be efficient and effective, intelligent and critical 
users of available software and resources, however, in order to realize the full learning potential of information technologies and to select the authoritative knowledge they need. One way for students to achieve these skills is through a short course in information technologies, or electronic searching, a course that contributes to the basic missions of schools.

\section{Search Skills and School Goals}

One of the major goals of schools is that students master the knowledge and processes deemed important. A short course in search skiils contributes to this goal in three ways. A course in electronic searching

- helps deliver content knowledge in the subject areas, computer literacy, and information literacy,

- develops students' cognitive skills through use of the full range of thinking skills in Bloom's taxonomy, and

- reinforces the ethical use of information in terms of academic honesty and respect for copyrighted materials, foundation blocks of the academic tradition and a knowledge society.

There is now research data that validates the contribution of school libraries and librarians to student learning and knowledge. The results of a recent study of school library programs in three American states (Colorado, Alaska, and Pennsylvania) clearly indicate that "test scores [of elementary and secondary students] increased as library media specialists spent more time teaching cooperatively with classroom teachers [and] teaching information technology skills independently of classroom teachers" (Hamilton-Pennell et al., 2000, p. 45). The greatest increase in student scores occurred in grade 11. In addition students scored higher on tests when there was an increase in total library media center staff per 100 students, size of the library media center collection $\ldots$, library media center operating expenses per student, [and] computers with access to library resources, databases, and the Internet (Hamilton-Pennell et al., 2000, p. 46).

The data analysis controlled for differences in the schools and communities by using multiple regression analysis. These studies indicate clearly that increased library collections and instruction result in improved student knowledge as measured on test scores. Earlier studies in Ohio and Colorado found a positive correlation between the funding of school libraries and student achievement (Brunning, 1994; Lance, 1994).

\section{Teacher-Librarians as Instructors}

Student use of a well-stocked library with instruction in information skills clearly furthers student learning and school missions. Why, however, should there be a course in electronic search skills, and why should the teacher-librarian teach it? First, not all students are comfortable on computers, and many of those who are rely on their own preferred methods. Quick and easy seems to be students' preferred search strategy: a keyword on a favorite search engine or in an online general encyclopedia. Students do not instinctively know how to search for academic resources, and even computer literate college students are not skilled and critical users of search engines (Levine, 1996; McCarthy et al., 1997; Woodard, 1996).

Second, programs, searching, and results are more numerous and complex than in the days of the card catalog and paper index, and in order to find the information they need .7. 
students need more sophisticated search and evaluation skills (Levine, 1996; McCarthy et al., 1997; Tenopir, 1998; Woodard, 1996). "Teachers and students, faced with the explosion of information technology, need guidance in accessing, evaluating, and using information in an effective and ethical way" (Harada \& Donham, 1998, p.15). Teacher-librarians are best able to teach such a course because their professional education includes information technologies and the evaluation of information materials. They have the knowledge and skills to enable students to become intelligent and critical searchers who can find the golden nugget of knowledge in the increasing glut of resources and information available.

Third, educators and others have done such a good job of promoting the Internet as a source of information that neither teachers nor students may be aware of its limitations for academic use and of the existence of numerous academically valuable subscription databases. Research has shown that (a) many students use only those resources they are aware of and (b) an important function of the teacher-librarian is to expand that awareness to new and appropriate resources (Howe, 1997; Coupe, 1993; Levine, 1996; McCarthy et al., 1997; Woodard, 1996).

Fourth, a separate course in searching would give English and social studies teachers more time to focus on the knowledge content of their curricula. Students would learn more literature and history if teaching search and research skills were not part of those courses. Moreover, teacher-librarians, as specialists in resources, access, and bibliography, have the skills to teach a search course that includes not only the process but also the documentation of research.

Fifth, knowledge and skills that are important for students to learn and use are usually presented in an organized way in a separate course. This is the reason for all courses in the curriculum. Since information skills are necessary to a knowledge society, a separate course seems to be a reasonable way for students to learn these basic skills. At the college level, academic librarians have found that brief instruction sessions are not effective and point-ofuse instruction is not a cost efficient use of the librarian's time (McCarthy et al., 1997). Moreover, all students should receive these skills at a given point in their program of study so that teachers may expect students to use them in subsequent courses. The disadvantage of integrating information skills into specific subject area courses at the secondary level is that it leads to some students who have had some exposure to basic information skills while others have had little or none at all. It is important that all students develop these skills, not just those whose teachers may bring them to the library for a resource-based learning project and let the teacher-librarian teach information skills (Howe, 1998).

Sixth, a separate course in research or search skills would emphasize that these skills are to be used for all research, not just a current assignment, and that students will be expected to use them in orher courses. There is evidence that information skills learned during a specific project are not generalized for use at other times (Fox \& Weston, 1993).

Finally, it is important to recognize the importance of knowledge in itself and how current technologies can both strengthen and undermine our knowledge. In Bloom's taxonomy of cognitive skills, Knowledge comes first, then Comprehension, Application, Analysis, Synthesis, and Evaluation (Bloom. 1956). There is a reason that knowledge comes first: accurate knowledge is the essential foundation upon which all the other thinking skills are based. In focusing on higher thinking skills, however, educators may have taken for granted the availability of accurate knowledge. In order to be successful, a knowledge society 
must use, communicate, and build on accurate knowledge. Knowledge can be confidently accumulated only when authenticated knowledge is selected and accurately transmitted. Quality collection development and student search, retrieval, and evaluation skills are essential to the location and use of accurate knowledge.

Current technologies, however, facilitate access to both high and low quality knowledge and expedite both the vanity press and plagiarism. Publication and dissemination of unreliable information is the first step on the slippery slope of misinformation that can undermine a knowledge society. The second step is the use and further transmission of that misinformation. College faculty are very concerned about student use of the Internet and some have forbidden it (Leckie \& Fullerton, 1999). When information of all levels of quality abounds and is accessible, it is all the more imperative that school libraries provide and promote the most authoritative and accurate resources and teach students to evaluate the resources they find beyond the school library collection and to select only the best.

Evaluation is possible, however, only when some knowledge already exists. Learners need to read authoritative resources before searching for and evaluating resources by themselves, and use of the school library collection plays an important role in developing this background knowledge. Evaluation of resources is a special skill developed and utilized by librarians, and they are therefore most qualified to teach this skill to others. In order to contribute to a knowledge society, teacher-librarians must perform the two essential roles of collection development and instruction in search and evaluation skills.

A short course may be the only way to achieve all these goals in secondary schools since there is often not adequate time to teach information skills to students when they come to the school library during a subject area class. Many secondary teacher-librarians have found that subject area teachers are reluctant to donate much time from the classes for information skills instruction, that they often prefer to have books delivered to the classroom or available on reserve, and that they may let students rely heavily on unevaluated websites. Consequently, secondary students may not get the practice they need searching, locating, and selecting academically appropriate resources.

\section{Academic Librarians as Instructors}

There is a similar lack of systematic instruction in search and research skills at the post-secondary level. Like high school teachers, college and university faculty have various and inconsistent approaches to information skills: they may present little or no instruction in their own classes, and they may or may not request that librarians provide some instruction for an assignment or library research project (Leckie \& Fullerton, 1999). While some colleges have developed a course in research and search skills, it may or may not be required of all students (Bush \& Wells, 1990; Clay et al., 1997; Martin, 1995; Ward \& Raspa, 1998; Woodard, 1996). Academic librarians at other colleges have developed online tutorials for information skills (Clay et al., 1997). The advice for academic librarians is to be flexible and to meet the specific requests of faculty rather than develop a systematic program of instruction in information skills (Leckie \& Fullerton, 1999).

In an age when both resource-based learning and the use of electronic resources is increasing, both secondary and post-secondary students are apparently not receiving the instruction they need to help them use information technologies effectively. All librarians K16 , however, have a role to play in creating an information literate populace (Gorman, 1995). Academic librarians and college faculty believe that their students should have some 
information skills when they arrive on campus (George, 1988; Leckie \& Fullerton, 1999; Levine, 1996). What should be the role of secondary school librarians, and how can they contribute the necessary skills to those who will work in a knowledge society?

\section{Concepts, Process, and Skills}

At the high school level, teacher-librarians can teach basic concepts, the research and search processes, and the specific skills of electronic searching that students can apply when using the available software. Such instruction should prepare students to use not only the resources in their school but also those they are likely to encounter in public and academic libraries, since our goal is that students become life-long learners and such instruction is less likely to be found in other libraries (Harris, 1992). Student knowledge of the concepts, process, and skills of information literacy is as important for those who do not go to college, and may not have further instruction, as for those who do go to colleges where instruction should build on what is learned in high school (Gorman, 1995; Levine, 1996). Transferability of skills is more likely when those skills are presented in a separate course within the context of general concepts that apply to other situations (Fox \& Weston, 1993; Jacobson \& Jacobson, 1993).

Teaching concepts to high school students is feasible because adolescents are in Piaget's abstract level of cognitive development (Elkind, 1994; Jacobson \& Jacobson, 1993; Woolfolk \& McCune-Nicolich, 1984). While integrating research skills into specific assignments may be more suitable for primary and elementary students, secondary students should be capable of understanding concepts and applying them both at the time of instruction and later. Concepts that can be presented and applied in an electronic search skills course include the structure and function of indexes and databases, the search process, the academic tradition, and the ethical use of information. These basic concepts lay a foundation for life-long learning and information literacy and should be made concrete through practical applications at the time of instruction (Jacobson \& Jacobson, 1993).

Knowledge societies and current information technologies have made it essential for students to learn and practice the ethical use of information and the academic tradition. Since many students dread the formulation of citations and bibliographies, it is important for them to understand the reasons for documentation and the ethical use of information:

- to identify resources consulted for a project

- to give credit for information, ideas, and words from another source

- to assure credibility of the researcher and the project by demonstrating the accurate use of authoritative resources,

- to provide information about resources consulted in a standard comprehensible format so that others may identify and locate those resources, and

- to obey copyright law.

The rationale for and the process of documentation rely heavily upon the use of accurate and authoritative knowledge since it is the foundation for building further knowledge.

\section{The Importance of Process}

Documentation is an important step in the process of research, and the use of an appropriate model of the research process during resource-based learning projects ensures that this step is not omitted. There are several models of the research process that can be used for instruction (Eisenberg \& Berkowitz, 1988; Harada \& Tepe, 1998; Herring et al., 2000). The use of a research model has other benefits as well. Recent research has demonstrated that 
use of the four-step PLUS model seems very effective at the middle school level in reducing plagiarism and generating more student knowledge of their topic. (Herring et al., 2000). Truett's research indicated that the use of a research model can counteract the observed increase in plagiarism and decrease in thought processes that result from increased use of technology (Bracy, 1996).

Just as using a model of the research process improves student learning and reduces their errors, using a process of electronic searching can improve searching for and selecting resources. Teaching students the steps in the search process provides a structure to searching that addresses bad search habits. Breaking down a procedure into its essential components helps prevent shortcuts and encourages the use of cognitive skills at each point in order to perform an intelligent and critical search.

I developed the following Seven Steps in the process of electronic searching in response to problems that students encountered as they searched, and I used them for five years in teaching a course in electronic search skills to ninth grade students:

- Step 1: Select a research topic and generate related search terms

- Step 2: Select a database appropriate for the topic and type of resource needed

- Step 3: Develop search strategies and statements

- Step 4: Retrieve and evaluate the results of the search

- Step 5: Modify the search to improve the results

- Step 6: Evaluate and select the citations of resources to be consulted

- Step 7: Cite and evaluate the resources consulted

Using these Seven Steps in the search process will require students to develop their knowledge of both their topic and the available resources, to use higher order thinking skills, and to utilize a variety of search strategies and statements in order to retrieve the most appropriate resources and information for their topic. Academic librarians have found that college students also need help with these aspects of electronic searching (Levine, 1996; McCarthy et al., 1997; Woodard, 1996).

While the resources and interfaces may change with the topic and times, this search process is likely to remain the same and can be applied to any topic. Moreover, the Seven Steps can be integrated into the more encompassing steps of the research process, which culminate in creating a product with new knowledge. While step one in both the search and research processes involves defining a topic of inquiry, search Steps $2-7$ are really an expansion of the next steps in research, identifying and locating the resources.

\section{Information Skills In and Beyond High School}

Another benefit of teaching electronic search skills centered around the process of searching is that such instruction builds knowledge of the general information skills needed by students in both high school and college:

- the ability to select and focus a topic,

- an awareness of the variety of library resources and services,

- a knowledge of the goals and structure of a classification system,

- comfort in asking questions in a library,

- a knowledge of the various indexes and their access points,

- correct use of search strategies and statements, including subject headings

- the ability to distinguish between book and journal citations, and

- the ability to locate and evaluate materials. 
Research by academic librarians has shown that college students often lack these basic skills and request both help with and more training in electronic searching (Allen, 1990; Bush \& Wells, 1990; Clay et al., 1997; Coupe, 1993; Dunn, 2002; Fox \& Weston, 1993; George 1988; Greer, Weston, \& Alm, 1991; Kenny \& Schroeder, 1992; Leckie \& Fullerton, 1999; Levine, 1996; McCarthy et al., 1997; Nash \& Wilson, 1991; Scott et al., 1995; Woodard, 1996).

Colleges and universities, as well as their librarians and the Association of College and Research Libraries, do recognize the importance of information literacy and competency skills for their students (Clay et al., 1997; Dunn, 2002). The California State University (CSU) system, which serves 370,000 students on 23 campuses, recently undertook a major study of their students' information skills because it identified "information competency as an action item and a critical skill for all students," one that will provide them with the tools to succeed in a "global and knowledge-based economy" (Dunn, 2002, 26). While college faculty generally believe that students should know how to do library research, they nonetheless observe that incoming college students have poor information skills (Leckie \& Fullerton, 1999).

High school teachers and librarians therefore have an important role to play in preparing their students for resource-based learning at the post-secondary level. The high school library is a place where students can learn information concepts and skills and gain experience in using library resources so that they can more easily use public and academic libraries after graduation (Levine, 1996). Students taking a short course in electronic searching can learn these information skills by applying the process, concepts, and search skills on the software and resources available in the school library.

\section{Planning, Teaching, and Assessment}

There are some basic considerations in developing a course. First, teach search skills to students the first year they are in a building in order to facilitate student awareness of library resources and to prevent the bad search habits that can develop when use precedes instruction. Second, students should have their own workstations so that they have multiple opportunities for searching the variety of databases available. Multiple sessions and databases are needed for students to master skills. Third, provide daily hands-on applications of the concepts and Steps after a demonstration. Academic librarians have recommended these guidelines for use at the college level as well (Leckie \& Fullerton, 1999; Levine, 1996; McCarthy et al., 1997; Woodard, 1996).

Teacher-librarians should ensure that students develop and use the full range of Bloom's cognitive skills when searching rather than just doing the easiest or quickest search using one keyword. They should also ensure that students learn the variety of available resources by having them use at least one of each of the basic genre: catalogs, periodical indexes or full-text databases, and search engines on the Internet for books, articles, and web sites. While students do learn some of the mechanics of specific software during use, it should not be assumed that the efficient and effective use of information software is intuitively obvious. Although using the Seven Steps will help students to learn to use the interfaces effectively, it would not be wise to focus instruction on the mechanics of specific software since they will likely change soon anyway. It is better to focus instruction on what is more permanent: the concepts, process, and skills of electronic searching (Woodard, 1996). Finally, teacher-librarians should integrate the product of searching, an annotated 
bibliography or research report, into courses across the curriculum by having students select a research topic from one of their current courses.

A syllabus prioritizes what is important for students to learn and organizes instruction meaningfully. The goal of the course is for students to develop both the conceptual framework and the specific skills needed to search effectively the on-line catalog, full-text databases, and Internet resources available in the school library. At the end of the course described below, students will be able to

$\square$
$\square$
$\square$
$\square$
understand the structure and functions of indexes, access points, and databases,
$\square$
search indexes, catalogs, databases, and the Internet for resources and locate
information in periodicals, books, full-text databases, and web sites,
$\square \quad$ prepare an annotated bibliography of the resources consulted, and
$\square \quad$ apply electronic search skills to other courses and libraries (Bolby et al., 1999).

A workbook gives students an outline of the course content and provides them with a worksheet to record search statements and results for each Step. To encourage critical thinking, each workbook page should have a reflection that is an open-ended evaluative question on the work done that day. Sample workbook pages for electronic searching may be found on the American Association of School Librarians website (www.ala.org/aasl/kqweb).

Assessment is based on two packets of materials submitted by the students. The Search Report contains the workbook pages for the daily searches and reflections, a review or test, and printouts of search results or citation lists (Bolby et al., 1999). It is graded on the quality of the search terms and search statements, the relevance of the citations printed from the hit lists, reflections, and performance on a written review or test.

The Research Report contains the workbook pages for the annotated bibliography or research paper, notes from a book, a reflection on what students learned about searching and their topic, and full-text copies of articles and a website selected for reading (Bolby et al., 1999). It is graded on the quality and relevance of the resources selected for reading, the correctness of bibliographic format, the completeness of the notes and annotations, and the reflection. The teacher-librarian may forward the Research Report to the teacher of the course related to the research topic.

\title{
Schedule of Topics
}

The following schedule organizes the Seven Steps into daily topics and assignments.

\author{
Topic/Day 1: Organization of the Course and Information Concepts \\ - Logistics and expectations of the course \\ - Information concepts: index, access points, database \\ - $\quad$ The Seven Steps in the electronic search process \\ - Ethical use of information: citing sources and abiding by copyright law
}

Step 1: Select a research topic and generate related search terms. After students select a research topic related to one of their courses, they should generate a variety of related search terms, including synonyms and narrower and broader terms. Check for relevance and comprehension by having students share their topics and related terms with the whole class. 
Topic/Day 2: Select a Database and Develop Search Strategies and Statements

Step 2: Select a database appropriate for the topic and the type of resource needed. The teacher-librarian should select a database that is appropriate for teaching each Step in the process. By the end of the course, however, students will have used a variety of databases and can select the ones they need in subsequent courses.

Step 3: Develop search strategies and statements. If students are to be intelligent and critical searchers, it is essential that they know the basic types of search strategies, how each operates, what kind of hits it will retrieve, and its advantages and disadvantages. The concepts to be introduced are the definitions and discussion of the subject heading and keyword search strategies. Use a database that clearly indicates these different types of search strategies. For example, SIRS has both a subject search and an advanced keyword search that allows separate keywords for the text, title and author fields. Many other databases (e.g., EBSCO, A Matter of Fact, and ProQuest) have similar capabilities.

After writing their search statements and yield in their workbooks, students should print the citations selected from their subject and keyword searches and write a reflection comparing the results. I have found that such reflections indicate that students often find keyword searches to be quicker and easier to generate but that subject searches often give a better yield with fewer more focused results.

\section{Topic/Day 3: Evaluation and Modification of Search Statements to Improve Yield}

Step 4: Retrieve and evaluate the results of the search. Prior use of the Internet has led most students to realize that more hits are not necessarily better. Now they will learn two ways of evaluating their searches that focus on the number of relevant hits (recall and the precision ratio). Students may calculate and compare the precision ratios of their keyword and subject searches in their workbook. Students should practice Steps 4 and 5 on an index or database that includes summaries since summaries are a good indicator of relevance.

Step 5: Modify the search to improve the results. It is necessary to modify searches if there are no hits, too many hits, or too many irrelevant hits (a low precision ratio). Another goal is to manipulate the search to generate a manageable relevant yield: enough for a choice but not too many to evaluate (10-20 hits). Present the strategies for reducing and increasing yield with Boolean operators. Demonstrate with a few searches that broader subject headings will not necessarily retrieve more hits than narrower subject headings. After writing their statements and yields, students should print the results of their best searches as citation lists and indicate in their reflection the modification techniques they used to improve the results.

Topic/Day 4: Evaluation and Selection of Periodical Citations

Step 6: Evaluate citations and select resources to be consulted. Evaluating periodical citations is the key to selecting the best articles on the topic. Link the standard means of evaluating resources (authority, scope, depth, currency, relevance) to each part of the citation and its related field in the database (source, subject heading, pages, publication year, summary). 
The software for Step 6 should be an index with the above fields visible for easy comparison of the hits. Students should write the subject and keyword statements and yields in their workbooks, but they should select and print only those citations for resources available in the school library since they will read one of these articles for their annotated bibliography or research paper. They should then select one article to read from their results in Step 6 and also one article from their results in Step 3. Their reflection should indicate the criteria used for selecting these two articles. Students may use the same or different software for Step 6 as for Steps 4 and 5, but there should be three different searches since the goals in each Step are different.

\section{Topic/Day 5: Searching Online Catalogs}

Searching for books differs from searching for magazine articles. Broad subject headings should be used to find a book with a few pages of information on the topic, and reference books will usually have even broader subject headings. Students can use the various subject headings given for a title as an indicator of relevance as well as scope since there may not be summaries on catalog records. Students should do both subject and keyword searches and select one book to use for their bibliography or research paper. In their reflection students should indicate how searching for books differs from searching for periodical articles and what criteria they used for selecting a title on their topic.

\section{Topic/Day 6: Locating and Using Resources in the Library Media Center}

On this day students retrieve the book and two articles they selected as the best for their topic. In this way they learn how to locate, use (take notes), and return resources in the library, copy articles, and print full-text.

\section{Topic/Day 7: Writing an Annotated Bibliography}

Step 7: Cite and evaluate the resources consulted. Present or review the bibliographic format from the school's preferred style manual. Students should write, in their own words, a four-sentence summary of each resource that includes the main idea(s) and other interesting information on their topic. They may add an evaluative sentence to each annotated citation.

\section{Topic/Day 8: Evaluation and Selection of Academically Valuable Internet Resources}

After having selected and read authoritative print resources, students will be better prepared to search for, evaluate, and select an academically valuable Internet resource on their topic. Demonstrate the category and domain searches and distinguish them from subject and keyword searches. Discuss the structure and functioning of search engines and how they differ from indexes. Present the standard evaluation criteria for information resources: authority, scope, date, depth, treatment, and accuracy. Students should then complete a workbook page using these criteria to evaluate the Internet resource they selected.

Topic/Day 9: Review and Continued Reading and Writing

Students should take a brief written review or test that includes questions on the concepts, process, and skills of electronic searching. They can use the rest of the period to prepare their bibliography or research paper and write a reflection on what they learned about searching and their topic. 
Students should use this class period to finish their workbook pages and annotated bibliography or research report. They should then assemble their workbook pages and citation printouts as the Search Report; they should assemble their annotated bibliography or research report and full-text copies of resources consulted as the Research Report (Howe, 2002)

\section{Collaboration, Integration, and Enhanced Learning}

Keith Curry Lance's studies of the correlation between library programs and student learning indicate that (a) student achievement is not dependent on demographics such as race or income level and (b) greater student learning occurs where teacher-librarians instruct students and there is collaboration between teacher-librarians and teachers (Hamilton-Pennell et al., 2000). While this paper advocates the instruction of search skills in a separate course rather than integrated into specific subject area courses at the secondary level, there are nonetheless two main avenues for collaboration and integration.

First, if instruction in electronic search skills is a unit of another course, it is important to discuss with the teacher of that course both the goals of the unit and its relationship to the teacher's course. Invite the teacher to sit in on the course and ask for his/her comments. In this way the teacher will see how the unit complements what he/she is doing, feel some understanding and ownership of the unit, and may promote its importance to students and other teachers. Discuss teaching strategies, student behavior, learning problems, and assessment with the teacher. While the teacher-librarian should grade the student's Search and Research Reports, these grades should be incorporated in the final grade for the teacher's course.

For example, if search skills are a unit in a computer science course, the teacherlibrarian should make explicit the similarities and differences between information databases and other basic types of software, such as word processing and spread sheets, which the other teacher presents. If search skills are part of a research project for an English course, the teacher-librarian may present the process of searching while the English teacher presents the research and writing process. If search skills are incorporated in a whole course on research, teacher-librarians and English teachers can collaborate by team teaching the course, with the teacher-librarian taking responsibility for instruction in research and search skills and an English teacher taking responsibility for the writing of a research paper.

Collaboration and team teaching are highly individualistic processes in which each partner has goals and skills to contribute. The results of collaboration and team teaching depend on the amount of time allocated for the search unit and the other topics in the course, the desired skills for students to attain, and the strengths each partner brings to the project.

Second, requiring that students select a research topic that is related to current study in one of their other courses leads to collaboration with teachers in all subject areas. It also leads to increased student learning of course-related knowledge. Teacher-librarians should discuss ahead of time with each teacher the range of possible topics for a Research Report related to their course so that the teacher-librarian can help direct or limit students' choice of research topics on the first day. Teacher-librarians may also discuss the possibility of teachers grading or giving extra credit for the knowledge presented in the Research Report. 


\section{Conclusions}

Searching for and selecting appropriate resources that provide accurate knowledge on a topic are essential skills for everyone entering a knowledge-based society, whether or not they go on to post-secondary education. Information technologies are available at home and in public libraries as well as school and academic libraries. School libraries and librarians, therefore, have an important role in imparting to all students the ethical and effective use of information technologies and resources. A course is the standard way of giving consistent instructional content to all students. Just as teaching students the process of research contributes to learning and helps prevent plagiarism, teaching students the process of searching is an important means to help learners search for and select the best relevant resources in the glut of information available. A short course in search skills can be integrated into existing courses in computer literacy, research, or English, and teacher-librarians can collaborate with teachers across the curriculum for possible research topics. Providing a firm foundation of information skills in high school through a short course in electronic searching will enable students to improve their use of resources in other libraries and become more skillful participants in a knowledge society.

Author's note: The section "Schedule of Topics" was previously published in Howe, E.B. (2000), The Goals and Mechanics of Teaching a Short Course in Electronic Search Skills to High School Students, Knowledge Quest: Journal of the American Association of School Librarians, 30(4), 38-41. Other sections of this paper are new and incorporate an updated review of the literature.

\section{Bibliography}

Allen, G. (1990). CD-ROM training: what do the patrons want? $R Q, 30(1), 88-93$.

American Association of School Librarians and Association for Educational Communications and Technology (1998). Information Power: Guidelines for school library media programs. Chicago: American Library Association.

Bolby, J., Howe, E., Szlachetka, D., \& Sutula, J. (1999, 1998, 1997, 1996, 1995). Computer Literacy I: Applications. Pittsburgh, PA: Shady Side Academy.

Bloom, B. (1956). Taxonomy of educational objectives. New York : David McKay.

Bracy, P. (1996). Discovered in North Carolina: An Overview of Research Related to School Library Media Programs. North Carolina Libraries 54 (1), 9-18.

Brunning, M. (1994). Is Money Spent on Libraries a Wise Investment? Ohio Media Spectrum, 46(3), 18-20.

Bush, R.B., \& Wells, M.R. (1990). Bibliographic instruction for honors students: The University of Buffalo experience. Research Strategies, 8(3), 137-143.

Clay, S.T., Harlan, S., \& Swanson, J. (1997). The Launching Pad: Delivering Information Competence through the Web. Librarians Association of the University of California, Santa Barbara. Conference, Santa Barbara, CA. Available: http://www.library.ucsb.edu/universe/clay.html. 
Coupe, J. (1993). Undergraduate library skills: Two surveys at Johns Hopkins University. Research Strategies, 11(4), 188-201.

Dunn, K (2002). Assessing Information Literacy Skills in the California State University: A Progress Report. Journal of Academic Librarianship, 28(1), 2635 .

Eisenberg, M.B., \& Berkowitz, R.E. (1988). Information problem-solving: The big six skills approach to library \& information skills instruction. Norwood, NJ : Ablex.

Elkind, D. (1994). A sympathetic understanding of the child: Birth to sixteen (3rd ed.). Boston : Allyn and Bacon.

Fox, L., \& Weston, L. (1993). Course-integrated instruction for nursing students: How effective? Research Strategies, 11(2), 89-99.

George, M. (1988). What do college librarians want freshmen to know? My wish list. Research Strategies, 6(4), 189.

Gorman, M. (1995). The domino effect, or why literacy depends on all libraries. School Library Journal, 4l(4), 27-29.

Greer, A., Weston, L., \& Alm, M. (1991). Assessment of learning outcomes: A measure of progress in library literacy. College \& Research Libraries, 52, 549-557.

Hamilton-Pennell, C. Lance, K.C., \& Rodney, M.J. (2000). Dick and Jane Go To the Head of the Class. School Library Journal 46 (4), 44-47.

Harada, V., \& Donham, J. (1998). Information Power: Student Achievement is the Bottom Line. Teacher Librarian, 26(1), 14-17.

Harada, V.H., \& Tepe, A.E. (1998). Information Literacy: Pathways to Knowledge. Teacher Librarian, 26(2), 9-15.

Harris, R.M. (1992). Bibliographic instruction: The views of academic, special, and public librarians. College \& Research Libraries, 53, 249-256.

Herring, J., Tarter, A.M., \& Naylor, S. (2000). Theory into Practice: Using the PLUS Model to Teach Information Skills and Support the Curriculum in a Secondary School. In E.B. Howe (Ed.) Information Literacy: Key to the Future (pp. 111118). Seattle, WA: International Association of School Librarianship, 2000.

Howe, E.B. (1997). Using student surveys to build and evaluate an information skills program. School Libraries Worldwide, 3(2), 68-77.

Howe, E.B. (1998). Integrating information technology into and across the curriculum: a short course for secondary students. Knowledge Quest: Journal of the American Association of School Librarians, 26 (2). 32-40. 
Howe, E.B. (2000). The Goals and Mechanics of Teaching a Short Course in Electronic Search Skills to High School Students. Knowledge Quest: Journal of the American Association of School Librarians, 30(4), 38-41.

Jacobson, F.F., \& Jacobson, M.J. (1993). Representative cognitive learning theories and BI: A case study of end user searching. Research Strategies, 11, 124-137.

Kenny, R.F., \& Schroeder, E. (1992). An evaluation of a training and assistance program for the CD-ROM databases: Reflections on the process. Reference Services Review, 20(2), 41-48.

Lance, K.C. (1994). The Impact of School Library Media Centers on Academic Achievement. School Library Media Quarterly, 22(3), 167-170.

Leckie, G.J., \& Fullerton, A. (1999). Informatioin Literacy in Science and Engineering Undergraduate Education: Faculty Attitudes and Pedagogical Practices. College \& Research Libraries, 60(1), 9-29.

Levine, C. (1996). What We Wish They Knew When They Got Here. North Carolina Libraries, 54(1), 19-21.

Martin, R.P. (1995). Integrating library computer skills into a credit course. Association of College and Research Libraries. National Conference, Pittsburgh, PA.

McCarthy, C.A., Krausse, S.C., and Little, A.A. (1997). Expectations and Effectiveness Using CD-ROMs: What Do Patrons Want and How Satisfied Are They? College \& Research Libraries, 58(2), 128-142.

Nash, S., \& Wilson, M.C. (1991). Value-added bibliographic instruction: Teaching students to find the right citations. Reference Services Review, 19(1), 87-93.

Scott, J., Trimble, J.A., \& Fallon, L. (1995). "@\&!\#@ this computer and the horse it rode in on": Patron frustration and failure at the OPAC. Association of College and Research Libraries. National Conference, Pittsburgh, PA.

Tenopir, C. (1998). Reference Use Statistics. Library Journal, 123(8), 32-34.

Ward, D., \& Raspa, R. (1998). Information Literacy: The Collaborative Imperative. NCA Quarterly, 72(4), 436-439.

Woodard, P. (1996). Librarian and Faculty Collaboration in Honors 301.88: An Interdisciplinary Computer Applications Course. Research Strategies, 14 (3), 132-144.

Woolfolk, A.E., \& McCune-Nicolich, L. (1984). Educational psychology for teachers (2nd ed.). Englewood Cliffs, NJ : Prentice-Hall. 